\title{
BMJ Open Risk of sarcoidosis and seropositive rheumatoid arthritis from occupational silica exposure in Swedish iron foundries: a retrospective cohort study
}

\author{
Per Vihlborg, Ing-Liss Bryngelsson, Lena Andersson, Pål Graff
}

To cite: Vihlborg $P$, Bryngelsson I-L, Andersson L, et al. Risk of sarcoidosis and seropositive rheumatoid arthritis from occupational silica exposure in Swedish iron foundries: a retrospective cohort study. BMJ Open 2017;7:e016839. doi:10.1136/ bmjopen-2017-016839

- Prepublication history for this paper is available online. To view these files please visit the journal online (http://dx.doi org/10.1136/bmjopen-2017016839).

Received 14 March 2017 Revised 29 May 2017 Accepted 30 May 2017
CrossMark

Faculty of Medicine and Health, Department of Occupational and Environmental Medicine, Örebro University, Örebro, Sweden

Correspondence to

Dr Pål Graff;

pal.graff@regionorebrolan.se

\section{ABSTRACT}

Objective To study the impact of occupational silica exposure on the incidence rates of sarcoidosis and rheumatoid arthritis (RA) in a cohort of exposed workers in Swedish iron foundries.

Design The prevalence of sarcoidosis and RA in a cohort of silica exposed workers was compared with the prevalence in the general Swedish population in this register study. A mixed model was used to calculate silica exposure, and individual silica exposures were used to compute dose responses.

Setting Personnel records from 10 iron foundries were used to identify workers whose employment began before 2005 which was then linked to the national non-primary outpatient visits register.

Participants The final cohort consisted of 2187 silicaexposed male workers who had been employed for at least 1 year and were still alive without having emigrated when the follow-up study began. The cohort's employment period covers 23807 person-years at risk.

Main outcome The presented results indicate that moderate to high levels of silica exposure increase risks for sarcoidosis and seropositive RA.

Results Mean levels of airborne silica dust in the foundries decreased significantly between the 1970s and 2000 s. Incidence rates of sarcoidosis $(3.94 ; 95 \% \mathrm{Cl}$ 1.07 to 10.08$)$ and seropositive $\mathrm{RA}(2.59 ; 95 \% \mathrm{Cl} 1.24$ to 4.76 ) were significantly higher among highly exposed individuals.

Conclusion Our results reveal increased risks for sarcoidosis and seropositive RA among individuals with high exposure to silica dust $\left(>0.048 \mathrm{mg} / \mathrm{m}^{3}\right)$ compared with non-exposed and less-exposed groups.

\section{BACKGROUND}

Sarcoidosis is an inflammatory disease that involves the formation of granulomas, mainly in the lungs and/or intrathoracic lymph nodes, but several other organs may also be affected. ${ }^{1}$ It is diagnosed by biopsy-usually via bronchoscopy if there is lung involvement. Sarcoidosis has no clear aetiology and it is estimated that it has an annual incidence of 11.5 per 100000 in Sweden. ${ }^{2}$ Its frequency peaks among individuals aged between 20 and 45
Strengths and limitations of this study

- This study identifies a possible trigger for sarcoidosis and seropositive rheumatoid arthritis (RA).

- This study draws on exposure measurements acquired at workspaces since 1968, which constitute a uniquely long-running data set.

- The diagnoses were based on data recorded in the Swedish national non-primary outpatient visits register, which is significantly more accurate than diagnoses based on questionnaires.

- The study's main weakness is that despite its relatively large sample size, the data set only includes a few cases of sarcoidosis as the diagnosis is rather unusual.

- As this study is a register study, it provides no indications of other exposures that can trigger RA and sarcoidosis.

years. Although its aetiology is unknown, it is believed to be multifactorial and potentially triggered by environmental factors in genetically predisposed individuals. ${ }^{13}$ One such suspected environmental factor is silica or silica dust, but only a few studies on silica and sarcoidosis have been published. However, administration of silica via the gastrointestinal tract or intravenously reportedly promotes granuloma development in mice infected with mycobacteria. ${ }^{4}$ There have also been reports of persistent sarcoidosis going into regression on cessation of silica exposure. ${ }^{56}$ Moreover, a cohort study of workers in a limestone (diatomaceous earth) quarry in Iceland found a sarcoidosis incidence rate of 9.3 per 100000 compared with just $0.5-2.7$ per 100000 for the Icelandic population as a whole. ${ }^{7}$ While this was taken to suggest that silica exposure may increase the risk for sarcoidosis, the sample was too small to draw firm conclusions. ${ }^{7}$ A large case-control study in the USA suggested that silica is associated with a range of diseases in addition to silicosis, including lung cancer, chronic obstructive 
pulmonary disease, pulmonary tuberculosis and the autoimmune disease rheumatoid arthritis (RA). ${ }^{8}$ While this study found that silica exposure increased risks for various autoimmune diseases (including systemic lupus erythematosus and systemic sclerosis), it did not indicate any connection with sarcoidosis.

Silica exposure is known to cause a fibrotic and potentially fatal lung disease called silicosis. ${ }^{9}$ Silicosis is currently rare in Sweden because of legislation against silica and silica dust exposure, which has successfully reduced occupational exposure levels. ${ }^{10}$ This legislation also requires people who are occupationally exposed to silica dust to undergo regular medical checks including physical examinations with spirometry and chest X-rays to ensure the absence of lung disease. ${ }^{11}$ To study the impact of occupational silica exposure on the risk of sarcoidosis, we used a cohort of silica-exposed workers from Swedish iron foundries. ${ }^{10}$

As silica exposure also putatively plays important roles in other inflammatory diseases such as RA, ${ }^{8}$ we also investigated the risk for RA in the studied cohort. RA and sarcoidosis are both inflammatory diseases, although with different symptoms. Thus, the environmental factors that trigger them in genetically predisposed individuals may be similar. $^{112}$

Earlier studies have shown that seropositive RA can be initiated within the respiratory system by autoimmune responses to citrullinated peptides. ${ }^{13}$ A Swedish cohort study found that silica exposure combined with smoking is associated with an increased risk of developing anticitrullinated protein antibody (ACPA)-positive RA. ${ }^{12}$

At our clinic, we have recently had some patients with pulmonary sarcoidosis who also experienced occupational exposure to silica. This prompted us to investigate whether silica dust could cause sarcoidosis, and since these patients now had sarcoidosis, whether it would be advisable for them to stop their occupational exposure to silica.

\section{Methods and statistical analysis}

Data from 10 iron foundries' lists of employees were available in this study. ${ }^{10}$ The foundries' personnel records were used to identify male workers whose employment began before 2005, yielding an initial cohort of 3966 subjects, of whom 1779 were excluded, for reasons shown in figure 1. Thus, the final cohort consisted of 2187

3966 employees had worked in the ten foundries from 1930 to 2013

We excluded

2 due to unclear identity

6 due to unclear working times

676 who had been employed for less than 1 year

861 employees died or emigrated before 2001

234 women

\section{7 lived and were registered in Sweden on 2001/01/01, when our study period began (the beginning of the study period coincides with the start of availability of reliable data on the incidence of sarcoidosis and RA). These were included in the study, resulting in a total of 23807 person-years at risk}

Figure 1 Selection of participants for inclusion in the cohort. 
silica-exposed male workers who had been employed for at least 1 year and were still alive without having emigrated when the follow-up study began. Overall, the cohort's employment period represents 23807 personyears at risk.

All Swedish residents have a unique personal identification number and equal access to healthcare and hospital services. This enables retrieval of patient data from various registers, providing unique opportunities to analyse morbidity across the entire patient population. Such nationwide patient registers are well suited for epidemiological studies.

The cohort was linked to the 'National non-primary outpatient care register', which is maintained and validated by the Swedish National Board of Health and Welfare, which contains data on registered outpatients of healthcare facilities throughout Sweden for all years since 2001. Sarcoidosis was defined according to the International Classification of Diseases, 10th Edition (ICD-10) D86 $(0,1,2,3,8)$ and RA M05 $(0,1,2,3,4,5,6,7,8$, 9) and M06 $(0,1,2,3,4,8,9)$. The sarcoidosis and RA morbidity analyses covered the period from 2001 (when the National non-primary outpatient care register started) through to 2013. Information on the workers' vital status and emigration status as of the 31 December 2013 was obtained from the Swedish population registry.

The follow-up period for each worker in the cohort began in 2001 or at the start of the worker's employment in the foundry, whichever came first. The follow-up period ended at the end of 2013 or on the date of the worker's death or emigration or on the date a diagnosis of either sarcoidosis or RA was registered if it occurred before then.

The person-years at risk were calculated and stratified according to gender, 5-year age groups and 1-year calendar periods. The expected numbers of people with sarcoidosis (classified as D86 under the ICD-10 standards) and RA (classified as M05 and M06 under the ICD-10 standards) for these strata were calculated using data for the general Swedish population as a reference (derived from the 'National non-primary outpatient care register'). Standardised incidence ratios (SIRs) with 95\% CIs were calculated on the assumption of a Poisson distribution of the observed numbers.

The silica exposure data used in this study were personal sampling measurements of respirable silica acquired between 1968 and 2006. The measurement times range from 240 to $600 \mathrm{~min}$ and were corrected to obtain 8 hour time weighted average (8-hour TWA) concentrations, representing exposures over a full workday. A total of 1667 silica measurements from the 10 foundries were included in the study.

A mixed model was used to calculate silica exposure concentrations for workers in 4 time periods (1968-1979, 1980-1989, 1990-1999 and 2000-2006) with different job titles (Swedish equivalents of: caster, core maker, fettler, furnace and ladle repairman, maintenance man, melter, moulder, sand mixer, shake-out operative, transportation worker, other specified, many jobs, foundry worker and other unspecified) in each of the 10 foundries. These concentrations were used to estimate the workers' average yearly silica exposures. Individual silica exposures $\left(\mathrm{mg} / \mathrm{m}^{3}\right)$ were used to calculate dose responses. Exposure to respirable silica was thus defined as the average exposure per year in $\mathrm{mg} / \mathrm{m}^{3}$ and categorised into four dose groups (quartiles) $:<0.023 \mathrm{mg} / \mathrm{m}^{3}, 0.024-0.035 \mathrm{mg}$ / $\mathrm{m}^{3}, 0.036-0.047 \mathrm{mg} / \mathrm{m}^{3}$ and $>0.048 \mathrm{mg} / \mathrm{m}^{3}$. Because we lack data from before 1968, exposure times before this year were estimated based on the silica level after 1968 . The exposures for the groups 'other specified', 'foundry workers' and 'other unspecified' were taken to equal the mean exposure for all the other job classes. The exposure measurement database and exposure modelling are presented elsewhere. ${ }^{15}$

\section{Involvement of patients}

No patients were involved in the design or conduct of this register study.

The study was approved by the Ethical Committee in Uppsala, Sweden; DNR 2015/066.

\section{RESULTS}

Most of the 2187 workers in the cohort began working at the foundries in the 1970s or 1980s, but some had started as early as during the 1930s (table 1). All the study participants were male. Almost half had been employed in the foundries for 2-10 years, but nearly $40 \%$ had worked in foundries for over 10 years (table 1). The total range of employment was 1 to 52 years and the mean duration of employment was 11 years. As shown in table 1, the cohort included workers representing a wide variety of job categories; the most frequent were fettler $(20 \%)$ and core maker $(11.3 \%)$. However, many of the workers had been employed in several capacities during the study period (table 1).

Silica exposure had been measured for workers of all the job categories, and was found to vary between 0.0054 and $4.9 \mathrm{mg} / \mathrm{m}^{3}$ (table 2). The highest measurements were well above the Swedish occupational exposure limit (OEL) of $0.1 \mathrm{mg} / \mathrm{m}^{3}$, but both the mean and median measurements for workers of most job categories were below the OEL, except for furnace and ladle repairmen (table 2). Furnace and ladle repairmen had the highest mean exposure in this study, but fettlers and sand mixers also had exposure values above the cohort mean (table 2).

Sorting the silica measurements according to their date of acquisition revealed that mean levels of airborne silica dust declined significantly over time, from $0.14 \mathrm{mg} / \mathrm{m}^{3}$ in the $1970 \mathrm{~s}$ to $0.073 \mathrm{mg} / \mathrm{m}^{3}$ in the $2000 \mathrm{~s}(\mathrm{p}<0.0001)$. Concomitantly, the median exposure to silica dust fell from $0.07 \mathrm{mg} / \mathrm{m}^{3}$ in the $1970 \mathrm{~s}$ to $0.028 \mathrm{mg} / \mathrm{m}^{3}$ in the 2000s (table 2).

The mean exposure varied between $0.033 \mathrm{mg} / \mathrm{m}^{3}$ and $0.15 \mathrm{mg} / \mathrm{m}^{3}$ and differed somewhat among the companies that participated in this study (table 2). 
Table 1 General information about the cohort

No of subjects Per cent

\begin{tabular}{|c|c|c|}
\hline \multicolumn{3}{|c|}{ Start of work (year) } \\
\hline 1930-1949 & 55 & 2.5 \\
\hline 1950-1969 & 425 & 19.4 \\
\hline 1970-1989 & 1035 & 47.3 \\
\hline $1990+$ & 672 & 30.7 \\
\hline
\end{tabular}

Years of employment

\begin{tabular}{|lrr|}
\hline $1-<2$ & 357 & 16.3 \\
\hline $2-10$ & 936 & 42.8 \\
\hline $11-20$ & 472 & 21.5 \\
\hline $20+$ & 422 & 19.3 \\
\hline Job categories & & \\
\hline Many jobs & 249 & 11.4 \\
\hline Caster & 64 & 2.9 \\
\hline Moulder & 209 & 9.6 \\
\hline Core maker & 246 & 11.3 \\
\hline Sand mixer & 7 & 0.3 \\
\hline Melter & 131 & 6.0 \\
\hline Furnace and ladle repairman & 6 & 0.3 \\
\hline Shake-out operative & 18 & 1.0 \\
\hline Fettler & 430 & 20.0 \\
\hline Maintenance man & 171 & 7.8 \\
\hline Transportation worker & 26 & 1.2 \\
\hline Other specified & 96 & 4.4 \\
\hline Foundry worker & 196 & 9.0 \\
\hline Office work & 48 & 2.2 \\
\hline Other unspecified & 290 & 13.2 \\
\hline
\end{tabular}

The airborne silica dust measurements presented in table 2 were used to derive estimated exposures for workers of all job categories in the cohort (as described in table 1) using a mixed model. The resulting estimated doses for each job category are shown in table 3 .

There is some job-dependent variation in estimated doses, but most of this variation relates to employment during the early stages of the measurement period (ie, before and during the 1970s).

For all cases, the concentration of respirable quartz derived from the mixed model based on employment duration, job title, time period, specific foundry and exposure time was expressed as an average annual exposure in milligram per cubic metre. There were seven cases of sarcoidosis in total among the cohort. This number was too small to permit analysis of risks' relationships with job categories or companies, but the sarcoidosis was distributed across the foundries. However, four of the patients with sarcoidosis were in the highest quartile for silica exposure, suggesting that exposure did increase the incidence of the disease (SIR 3.92; 95\% CI 1.07 to 10.03) (table 4).
We found an increased risk of RA, apparently due to airborne silica exposure, in our cohort (30 cases; SIR 1.52, $95 \%$ CI 1.00 to 2.21). When we investigated seropositive RA and seronegative RA separately; we found a statistically significant increase in risk for seropositive RA (18 cases; SIR $1.70,95 \%$ CI=1.01 to 2.69), but not seronegative RA (12 cases; SIR 1.41, 95\% CI=0.68 to 2.59). The incidence of seropositive RA was then related to silica exposure by dividing the cohort into quartiles, as previously done for sarcoidosis. Here again we observed increasing incidence with higher exposure. The increased risk of seropositive RA was significant (SIR 2.59, 95\% CI=1.24 to 4.76) for the most exposed group (exposure above $0.048 \mathrm{mg} / \mathrm{m}^{3}$ per year; see table 5). No such dose-dependent risk was observed for seronegative RA (data not shown).

\section{DISCUSSION}

The results of this work indicate dose-response relationships between silica exposure and incidence of both sarcoidosis and RA in Swedish foundry workers. This is consistent with suggestions in several previous case and population studies of a link between the incidence of sarcoidosis and silica exposure. ${ }^{5-8}$ Another study found no such correlation, ${ }^{9}$ but an endpoint in that study was death, which may explain the lack of a detected correlation as since sarcoidosis rarely causes death. It has been suggested that sarcoidosis might be caused by exposure to an exogenous factor in individuals who are genetically susceptible. ${ }^{13}$ Our study suggests that silica may be one such factor. Because the cases of sarcoidosis identified in this work were distributed across the foundries, rather than forming clusters associated with individual plants, we exclude the possibility that the observed incidence rates could be due to a local cluster.

Several studies have linked RA with silica exposure, ${ }^{912} 13$ putatively because some factor associated with silica exposure (and smoking) may induce an immunological response to citrullinated antigens, leading to the onset of seropositive RA (ACPA-positive RA). We also found that workers with the highest levels of silica exposure had the highest risk for seropositive RA. We lack complete information on the workers' smoking habits, but as the prevalence of smoking has decreased over time, as well as silica exposure, the proportion of smokers (or ex-smokers) may be highest in the highly exposed group, which could affect the prevalence of RA.

A potential causative mechanism of both seropositive RA and sarcoidosis is activation of an immune response in genetically predisposed individuals by an inhaled exogenous substance. As noted above, our results suggest that inhaled silica dust may be such a causative exogenous factor.

A strength of the study is that it draws on exposure measurements acquired at workspaces since 1968, which constitute a uniquely long-running data set. Moreover, the diagnoses were based on data recorded in the national non-primary outpatient visits register, which is 
Table 2 Measurements of silica exposure for workers of indicated job categories $\left(\mathrm{mg} / \mathrm{m}^{3}\right)$

\begin{tabular}{|c|c|c|c|c|c|c|}
\hline & $\mathbf{n}$ & Mean & Median & Minimum & Maximum & SD \\
\hline \multicolumn{7}{|l|}{ Job title } \\
\hline Caster & 68 & 0.033 & 0.018 & 0.0054 & 0.17 & 0.038 \\
\hline Core maker & 171 & 0.024 & 0.017 & 0.003 & 0.19 & 0.023 \\
\hline Fettler & 573 & 0.087 & 0.039 & 0.0025 & 2.1 & 0.16 \\
\hline Furnace and ladle repairman & 71 & 0.42 & 0.12 & 0.0028 & 4.9 & 0.76 \\
\hline Melter & 111 & 0.052 & 0.022 & 0.0038 & 0.52 & 0.079 \\
\hline Transportation worker & 29 & 0.031 & 0.023 & 0.0018 & 0.11 & 0.022 \\
\hline Maintenance man & 67 & 0.054 & 0.029 & 0.0052 & 0.67 & 0.09 \\
\hline Shake-out operative & 148 & 0.079 & 0.037 & 0.0047 & 3.3 & 0.29 \\
\hline 1970-1979 & 303 & 0.14 & 0.07 & 0.003 & 3.3 & 0.26 \\
\hline 1980-1989 & 347 & 0.08 & 0.027 & 0.0036 & 4.9 & 0.31 \\
\hline 1990-1999 & 472 & 0.062 & 0.026 & 0.0018 & 1.9 & 0.16 \\
\hline 2000-2006 & 545 & 0.073 & 0.028 & 0.0033 & 2.1 & 0.2 \\
\hline \multicolumn{7}{|l|}{ Company } \\
\hline 1 & 135 & 0.065 & 0.044 & 0.0035 & 0.29 & 0.062 \\
\hline 2 & 53 & 0.075 & 0.035 & 0.0054 & 0.89 & 0.14 \\
\hline 3 & 213 & 0.088 & 0.05 & 0.0083 & 0.98 & 0.13 \\
\hline 4 & 250 & 0.15 & 0.047 & 0.0038 & 4.9 & 0.43 \\
\hline Total & 1667 & 0.083 & 0.033 & 0.0018 & 4.9 & 0.23 \\
\hline
\end{tabular}

significantly more accurate than diagnoses based on questionnaires. Finally, the results were compared with data for the general Swedish population in the corresponding years, which allowed us to account for annual variation.

The study's main weakness is that despite its relatively large sample size, the data set includes only a few cases of sarcoidosis. We assume that the reference group was unexposed, but there were probably some silica-exposed individuals in this group too. As this study is a register study, it provides no indications of other exposures that can trigger RA and sarcoidosis.

It is possible that some of the sarcoidosis cases considered in this work are asymptomatic patients whose condition was only detected because silica-exposed workers are required to undergo mandatory health checks, including chest X-rays, which could result in overestimation of the risk for sarcoidosis. However, because workers are required to have a health check (including an
X-ray examination) before starting work in a job involving exposure to silica dust, we believe that such asymptomatic cases would probably be detected before the individual in question started working. We therefore assume that all the sarcoidosis cases identified in this study developed after the individuals in question began working at the foundries.

The increased risk for sarcoidosis cannot be explained by the X-rays that employees in the studied occupations undergo. We saw no increased incidence of sarcoidosis among the low-exposure groups, who were required to have the same number of chest X-rays as the high-exposure workers; thus, chest X-rays cannot explain the silica dust dose-related differences in incidence between the high-exposure and low-exposure groups. Additionally, the sarcoidosis sufferers had been working at the foundries for the same length of time as the rest of the cohort (the mean working time for both groups was 11 years), so 
Table 3 Estimated silica dose per year $\left(\mathrm{mg} / \mathrm{m}^{3}\right)$ for workers of indicated job categories based on a mixed model

\begin{tabular}{lrlllll}
\hline Job title & $\mathbf{n}$ & Mean & Median & Minimum & Maximum & SD \\
\hline Many jobs & 249 & 0.04 & 0.039 & 0.017 & 0.12 & 0.013 \\
Caster & 64 & 0.028 & 0.023 & 0.015 & 0.06 & 0.012 \\
Moulder & 209 & 0.042 & 0.032 & 0.018 & 0.098 & 0.023 \\
Core maker & 246 & 0.023 & 0.02 & 0.012 & 0.061 & 0.0096 \\
Sand mixer & 7 & 0.068 & 0.063 & 0.052 & 0.089 & 0.016 \\
Melter & 131 & 0.03 & 0.026 & 0.016 & 0.085 & 0.015 \\
Furnace and ladle repairman & 6 & 0.15 & 0.14 & 0.11 & 0.21 & 0.033 \\
Shake-out operative & 18 & 0.056 & 0.054 & 0.026 & 0.1 & 0.022 \\
Fettler & 430 & 0.044 & 0.037 & 0.023 & 0.12 & 0.016 \\
Maintenance man & 171 & 0.041 & 0.036 & 0.021 & 0.077 & 0.016 \\
Transportation worker & 26 & 0.038 & 0.044 & 0.019 & 0.059 & 0.012 \\
Other specified & 96 & 0.04 & 0.036 & 0.021 & 0.089 & 0.016 \\
\hline Foundry worker & 196 & 0.056 & 0.06 & 0.024 & 0.1 & 0.017 \\
\hline Office work & 48 & 0.037 & 0.033 & 0.021 & 0.073 & 0.011 \\
\hline Other unspecified & 290 & 0.038 & 0.028 & 0.02 & 0.11 & 0.021 \\
\hline
\end{tabular}

Table 4 Incidence of sarcoidosis in the cohort, grouped by yearly average exposure to airborne silica dust

\begin{tabular}{|c|c|c|c|c|c|c|}
\hline Mean silica $\left(\mathrm{mg} / \mathrm{m}^{3}\right)$ per year* & $\mathbf{n}$ & Person-years & Observed & Expected & SIR & $95 \% \mathrm{Cl}$ \\
\hline Total & 2187 & 23748 & 7 & 4.98 & 1.41 & 0.56 to 2.89 \\
\hline $0.012-0.023$ & 546 & 6279 & 0 & 1.38 & - & - \\
\hline $0.036-0.047$ & 547 & 5889 & 2 & 1.24 & 1.62 & 0.20 to 5.84 \\
\hline $0.048+$ & 547 & 5439 & 4 & 1.02 & 3.94 & 1.07 to 10.08 \\
\hline
\end{tabular}

${ }^{*}$ Average annual silica exposure $\left(\mathrm{mg} / \mathrm{m}^{3}\right)$, divided into quartiles.

$\mathrm{SIR}$, standardised incidence ratio.

Table 5 Incidence of seropositive rheumatoid arthritis in the cohort, grouped by yearly average exposure to airborne silica dust

\begin{tabular}{|c|c|c|c|c|c|c|}
\hline Mean silica $\left(\mathrm{mg} / \mathrm{m}^{3}\right)$ per year* & $\mathbf{n}$ & Person-years & Observed & Expected & SIR & $95 \% \mathrm{Cl}$ \\
\hline $0.012-0.023$ & 546 & 6267 & 2 & 1.667 & 1.20 & 0.15 to 4.32 \\
\hline $0.036-0.047$ & 547 & 5868 & 5 & 2.70 & 1.86 & 0.60 to 4.33 \\
\hline $0.048+$ & 547 & 5410 & 10 & 3.90 & 2.59 & 1.24 to 4.76 \\
\hline
\end{tabular}

*Average annual silica exposure $\left(\mathrm{mg} / \mathrm{m}^{3}\right)$, divided into quartiles.

SIR, standardised incidence ratio.

they would have been subjected to the same number of X-ray examinations.

\section{CONCLUSION}

Our results reveal increased risks for sarcoidosis (SIR 3.94, 95\% CI 1.07 to 10.08 ) and seropositive RA (SIR $2.59,95 \%$ CI 1.24 to 4.76 ) among individuals with high exposure to silica dust $\left(>0.048 \mathrm{mg} / \mathrm{m}^{3}\right)$ compared with non-exposed and less-heavily exposed groups.

Correction notice This article has been corrected since it was first published.
Figure 1 has been replaced.

Contributors PV, I-LB and PG conceived and designed the study. LA was responsible for the data collection. I-LB did the main data analysis. PV, I-LB and PG interpreted the results. PV, I-LB and PG wrote manuscript with input from LA. All authors approved the final version.

Funding This study was done with support from Region,Örebro County (OLL554311).

Competing interests None declared.

Ethics approval Ethical Committee in Uppsala, Sweden; DNR 2015/066.

Provenance and peer review Not commissioned; externally peer reviewed. 
Data sharing statement № additional data from this study are available.

Open Access This is an Open Access article distributed in accordance with the Creative Commons Attribution Non Commercial (CC BY-NC 4.0) license, which permits others to distribute, remix, adapt, build upon this work non-commercially, and license their derivative works on different terms, provided the original work is properly cited and the use is non-commercial. See: http://creativecommons.org/ licenses/by-nc/4.0/

(c) Article author(s) (or their employer(s) unless otherwise stated in the text of the article) 2017. All rights reserved. No commercial use is permitted unless otherwise expressly granted.

\section{REFERENCES}

1. Valeyre D, Prasse A, Nunes H, et alLancet 2014;383:1155-67.

2. Arkema EV, Grunewald J, Kullberg S, et al. Sarcoidosis incidence and prevalence: a nationwide register-based assessment in Sweden. Eur Respir J 2016;48:1690-9.

3. SwedishRespiratorySociety. National guidelines for treatment of Sarcoidosis, 2014.

4. Yeager H, Gopalan S, Mathew P, et al. Sarcoidosis: can a murine model help define a role for silica? Med Hypotheses 2012;78:36-8.

5. Solà R, Boj M, Hernandez-Flix S, et al. Silica in oral drugs as a possible sarcoidosis-inducing antigen. Lancet 2009;373:1943-4.
6. Drent $\mathrm{M}, \mathrm{Wijnen} \mathrm{PA}, \mathrm{Boots} \mathrm{AW}$, et al. Cat litter is a possible trigger for sarcoidosis. Eur Respir J 2012;39:221-2.

7. Rafnsson V, Ingimarsson O, Hjalmarsson I, et al. Association between exposure to crystalline silica and risk of sarcoidosis. Occup Environ Med 1998;55:657-60.

8. Calvert GM, Rice FL, Boiano JM, et al. Occupational silica exposure and risk of various diseases: an analysis using death certificates from 27 states of the United States. Occup Environ Med 2003;60:122-9.

9. Leung CC, It Y, Chen W, et alLancet 2012;379:2008-18.

10. Andersson L, Bryngelsson IL, Ohlson CG, et al. Quartz and dust exposure in swedish iron foundries. J Occup Environ Hyg 2009;6:9-18.

11. SwedishWorkEnvironmentAuthority. 2005. Medical Assessment in the Workplace.

12. Stolt $P$, Yahya A, Bengtsson $C$, et al. Silica exposure among male current smokers is associated with a high risk of developing ACPApositive rheumatoid arthritis. Ann Rheum Dis 2010;69:1072-6.

13. Perry E, Kelly C, Eggleton P, et al. The lung in ACPA-positive rheumatoid arthritis: an initiating site of injury? Rheumatology 2014;53:1940-50.

14. Westberg $\mathrm{H}$, Andersson L, Bryngelsson IL, et al. Cancer morbidity and quartz exposure in swedish iron foundries. Int Arch Occup Environ Health 2013;86:499-507.

15. Andersson L, Bryngelsson IL, Ngo Y, et al. Exposure assessment and modeling of quartz in swedish iron foundries for a nested casecontrol study on lung Cancer. J Occup Environ Hyg 2012;9:110-9. 